\title{
Studying the Mineral Additives Effect on a Composition and Properties of a Composite Binding Agent
}

\author{
AIMENOV ASKAR ZHAMBULOVICH ${ }^{1 *}$, KHUDYAKOVA TATYANA MIKHAILOVNA ${ }^{1}$, \\ SARSENBAYEV BAKYTZHAN KUDAIBERGENOVICH ${ }^{1}$, DZHAKIPBEKOVA NAGIMA \\ ORMANOVNA ${ }^{1}$, ALI KHALID ABDUL KHALIM KHEIDAR ${ }^{2}$ \\ and ALVEIN YASER MUKHAMED ALI ${ }^{3}$
}

${ }^{1} \mathrm{M}$. Auezov South Kazakhstan State University, Shymkent, Kazakhstan.

${ }^{2}$ Aden University, Aden, Republic of Yemen.

${ }^{3}$ Aden college community, Aden, Republic of Yemen.

${ }^{*}$ Corresponding author E-mail: stroitelstvo_ukgu@ mail.ru

http://dx.doi.org/10.13005/ojc/3404031

(Received: April 20, 2018; Accepted: June 30, 2018)

\begin{abstract}
A Portland cement is a basic initial component for concrete and reinforced concrete manufacture, which defines their technical-economic and operational properties. One of a perspective ways of increase in the efficiency of cement production without essential change of its technology is inclusion of various mineral additives influencing on a structure and properties of a cement stone. As power inputs make the most part of the costs necessary for cement manufacture, the cement industry is interested in decrease in fuel and electric power expenditures per 1 tonne of cement. To reach the decrease in power inputs and at the same time to raise the environmental safety of cement production the cement industry is recently focused on increase in output of composite cements. Composite cements not only promote optimization of the production in terms of ecology, but also can provide such technical advantages as lower hydration heat, higher chemical resistance and placeability.
\end{abstract}

Keywords: Sulphates, Sodium hydroxide, Dispersion, Mineral additive, Peptization, Disperse system.

\section{INTRODUCTION}

Cement industry is a basic branch of the building complex. To raise the efficiency of the cement industry it is necessary to increase output of mixed cements, to use more widely various industrial wastes as raw materials and active additives.
Available world trends in cement production include growth of output of multicomponent cements. Forecasts suggest that a share of multicomponent cements in the near future will make $75-80 \%$ of the total cement production volume, and additive-free cements will be used only for special purposes.

This is an Open Access article licensed under a Creative Commons Attribution-Non Commercial-Share Alike 4.0 International License (https://creativecommons.org/licenses/by-nc-sa/4.0/), which permits unrestricted Non Commercial use, distribution and reproduction in any medium, provided the original work is properly cited. 
Ferrous and non-ferrous metallurgical slags, ashes of thermal power plants, various volcanic and sedimentary rocks such as diatomites and other compounds are used as additives at cement manufacture.

To date it has been found that application of additive-free clinker cement in a pure state is not practical for a great number of working conditions of the cement and concrete on its basis in various buildings and engineering structures. Consequently, development and study of new additives improving quality of portland cement and concrete on its basis are relevant and timely.

Already for 70 years it is known that production and use of multicomponent cements with maximum content of additives can reduce total costs and prime cost of the produced products more significantly than transition from a wet cement production way to a dry one, which saves $35-40 \%$ of power, but it is much more capital-intensive. In a number of countries the transition from ordinary portland cement to multicomponent cement has been accomplished: in India, Belgium, some countries of Central and South America a share of multicomponent cements, containing $30 \%$ and more of active mineral additives, exceeds $70 \%$ of the total output ${ }^{1}$.

\section{New active mineral additives are}

1. Zeolitized rocks used alone or in combination with conventional active mineral additives.

2. Slags of non-ferrous metallurgy - this active mineral additive is suitable for high-alit clinkers and for heat wet treatment if warm-up temperature is not more than $45^{\circ} \mathrm{C}$.

3. Clay slates with high alumina content, previously known abroad.

4. limestone - a mineral additive relatively new for the cement industry. This filler is allowed by a European pre-standard for cement (pEN 197-92).

In view of the fact that power costs are the largest part of cement production cost, the cement industry is more than ever interested in reducing fuel and power consumption per tonne of cement.
At the same time the technological potential for decrease in power intensity is practically exhausted.

Currently in Europe, for economic and environmental reasons, there are changes in assortment of produced and consumed cements. The development of this direction has been accelerated by introduction of a new European standard EN 197-1, which has been applied for standardization of 27 cement types for general construction purposes. In accordance with the EN 197-1, alongside with a clinker, a granular blast-furnace slag, pozzolan as, fly ash, calcined slate, micro silica and limestone can be used as main cement constituents.

The largest share in sale of CEM II cements of 32.5 class belongs to a Portland cement with addition of limestone in quantity of $45 \%$. Composite $31 \%$ portland cements, containing more than two basic components, are in the second place and a share of these cements has increased especially in recent years. These cements (CEM II/K) alongside with further resource saving have the advantage that several basic components can be used in various beneficial combinations and positively effected on concrete properties. Portland cements with slag additives account for $32.5 \%-9 \%$ of cement sales, other CEM II cements - with addition of fly ash, slates, pozzolana $-15 \%$.

The largest share in the sale of CEM II cements of 42.5 class belongs to Portland cements containing limestone $-52.6 \%$. Cements containing fly ash are also in demand $-17 \%$. Portland cements containing slag and pozzolana play an insignificant role in this strength grade. A market share of each of them is $6.5 \%$.

To some extent this situation in the European sale market is due to economic factors and, possibly, because of absence of significant quantities of granulated blast furnace slag in a number of European countries. But positive properties of such the cements and concretes on their basis also play an important role ${ }^{2}$.

It is found that limestone is not an inert diluent. During hydration of a portland cement it reacts with tricalcium aluminate and forms 
calcium hydrocarboaluminates. In this case both a high-carbonate form of hydrocarboaluminate $\mathrm{C}_{3} \mathrm{~A} \cdot 3 \mathrm{CaCO}_{3} \cdot 32 \mathrm{H}_{2} \mathrm{O}$ - and a low-carbonate form $\mathrm{C}_{3} \mathrm{~A} \cdot \mathrm{CaCO}_{3} \cdot 12 \mathrm{H}_{2} \mathrm{O}$ - are formed. Physical properties of these modifications are similar to a high-sulphate form (ettringite) and a monosulphate form of calcium sulfoaluminates ${ }^{3}$.

Addition of limestone to cement, similar to a gypsum addition, can have a regulating effect on cement setting and $\mathrm{C}_{3} \mathrm{~A}$ and $\mathrm{C}_{3} \mathrm{~S}$ hydration rates. The best effect from the use of limestone is achieved at increased $\mathrm{C}_{3} \mathrm{~A}$ content in a clinker.

Studies of foreign scientists and experience of wide use of the limestone Portland cements in Europe have shown that they can be applied for manufacture of high-quality concrete with high physical and mechanical properties.

Limestone has some activity, taking part in formation of calcium hydro carboaluminates. An important factor is the absence of carbonatization of pre-hydrates (active nuclei of calcium hydrosilicates) formed at grinding multicomponent cements due to hydration by air.

In recent years calcium carbonate $\mathrm{CaCO}_{3}$ as limestone is increasingly used as a mineral additive at cement production. In accordance with State Standard $31108-2003$ it is permitted to add $6-20 \%$ (weight) of limestone in cement of CEM II/A-I type; for cement of CEM II/A-K type - up to $20 \%$ of limestone in combination with other mineral additives; in other cements - up to $5 \%$.

Works ${ }^{4,5}$ contain information that cements with limestone additives in strength characteristics, corrosive and frost resistance are as good as additive-free cements, if grinding fineness of a clinker component in composition of such the cements is equal to grinding fineness of this component in a standard cement.

Until now, there is no an unequivocal opinion on whether there is a chemical interaction between the cement hydration products with calcium carbonate or the latter acts as an inert additive that improves a structure of the hardened cement stone.
H. Uchikawa ${ }^{6}$ notes improvement of a porous structure of a hardened cement stone with limestone additives, but at the same time he denies chemical interaction of $\mathrm{CaCO}_{3}$ with the Portland cement hydration products. The research of $\mathrm{H}$. Kuzel shows ${ }^{7}$ that calcite is able to react with an AFm phase of a hardened cement stone giving solid solutions with different compositions. The work of V.V. Timashev and V.M. Kolbasov ${ }^{8}$ also confirms the possibility of $\mathrm{CaCO}_{3}$ interaction with minerals of a Portland cement clinker during the cement hydration. It is also noted that carbonate additives are particularly effective for high-aluminate cements.

In a number of works it is stated that calcium carbonate increases ettringite stability in a hardened cement stone ${ }^{5,9}$.

The authors have found that small amounts (3.5-4.5\%) of $\mathrm{CaCO}_{3}$, introduced into cement, have a positive effect on its properties. In this case calcium carbonate acts as an active component, forming calcium hydro carboaluminates with various compositions, which consolidates a hardened cement stone structure. Increase in $\mathrm{CaCO}_{3}$ content in cement leads to the fact that it begins to act as an inert additive. At a moderate $\mathrm{CaCO}_{3}$ content and a necessary granulometric composition (a size of Portland cement grains must be less than a size of calcite grains), such the additive can improve a microstructure and properties of the hardened cement stone. However, further increase in the additive amount causes deterioration of cement properties, including at the expense of density reduction and increase in porosity of the hardened cement paste ${ }^{10}$.

The most rational way is mechanochemical processing a Portland cement clinker. Its transportation is much easier than cement transportation, a clinker can be stored for years, in addition it becomes possible to involve actively local siliceous additives - both natural rocks and ashes and various slags - in cement manufacture. Such the manufacturing scheme was used in the last century in France and now it is widely applied in China: a clinker is produced at powerful enterprises, $50-70 \%$ of it is ground into cement, and the remained clinker is sold to small enterprises, which process it into cement introducing local mineral additives. Going into operation of such 
the workshops is of great practical importance, as today cement is a key building material. Realization of the new technology is particularly relevant in connection with the issue of SS 31 108-2003, which significantly expands the possibilities of introducing cheap local mineral additives and technogenic silica-containing components into a cement composition (with maintenance of a clinker part within $35-40 \%$ of mass of CEM III and CEM V cements) ${ }^{11,12}$.

It is difficult to overestimate the economic and environmental benefits of the mechanochemical processing of cement during grinding a clinker or regrinding the cements with significant content of siliceous rocks and, especially, wastes: ashes and slags, that reduce power specific costs for cement production with simultaneous improvement of its construction and technical properties (activity, strength, storage duration).

Materials and methods. The cement PC500 AF and the Portland cement clinker, produced on a LP "Standard Cement", and local materials dolomite of a Yany-Kurgan deposit and industrial wastes such as polymetallic ores' concentration tails, an electro thermal phosphoric slag and a soda-sulphate mixture have been used as initial raw materials.

The research has been implemented with application of standard testing procedures of silicate materials such as chemical, X-ray phase and electronic microscopic analysis. The cement's physicomechanical properties, setting time and compression strength for cubic samples in the size of $2 \times 2 \times 2 \mathrm{~cm}$ have been studied.

The X-ray phase examination has been carried out on an X-ray diffractometer "DRON-3", the electronic microscopic investigation - on a scanning electronic microscope JSM-6490LV with systems of energy dispersion microanalysis INCA Energy and structural analysis HKL-Basic. Physicomechanical tests of the samples have been realized on a press PGM-100MG4-A.

\section{RESULTS}

Scientists of SRI "Building Materials, Construction and Architecture" have studied the possibility of using the dolomite and the wastes formed at concentration of polymetallic ores as a carbonate additive during the grinding a clinker. In accordance with the European standard EN-197-1 carbonate-containing additives are usually limestone additives. Considering that dolomite is a widespread rock and an associated mineral of limestone, studying of influence of dolomite and the polymetallic ores's concentration wastes containing dolomite and calcite on the cement processing characteristics is of great importance ${ }^{13,14}$.

The Portland cement chemical and mineralogical composition is represented in Tables 1 and 2.

\section{Table 1: The PC chemical composition}

\begin{tabular}{lcccccccc}
\hline Portland cement type & \multicolumn{10}{c}{ Content of oxides, mas. \% } \\
\hline & $\mathrm{MgO}$ & $\mathrm{CaO}$ & $\mathrm{Fe}_{2} \mathrm{O}_{3}$ & $\mathrm{Al}_{2} \mathrm{O}_{3}$ & $\mathrm{SiO}_{2}$ & $\mathrm{SO}_{3}$ & $\mathrm{CaO}_{\mathrm{CB}}$ & $\mathrm{R}_{2} \mathrm{O}$ \\
PC500 AF & 1,28 & 65,65 & 4,53 & 4,67 & 22,1 & 0,38 & 0,16 & 0,73 \\
LP "Standard Cement" & & & & & & &
\end{tabular}

Table 2: The PC mineralogical composition

\begin{tabular}{lllll}
\hline Portland cement type & \multicolumn{4}{c}{ Content of minerals, mas. \% } \\
\hline C3S & C2S & C3A & C4AF \\
PC500 AF & 63,0 & 16,0 & 4,7 & 14,0 \\
LP "Standard Cement" & & & \\
\hline
\end{tabular}

Judging by the X-ray pattern the Portland cement contains such minerals as $\mathrm{C}_{3} \mathrm{~S}$ alite $(d=3,018 ; 2,780 ; 2,747 ; 2,641 ; 2,181 ; 1,762 \AA), C_{2} S$ belite $(d=2,747 ; 2,598 ; 2,181 ; 1,929 ; 1,623 \AA), C_{4} A F$ calcium alumoferrite $(\mathrm{d}=2,641 ; 1,929 ; 1,722 \AA), \mathrm{C}_{3} \mathrm{~A}$ calcium aluminate $(\mathrm{d}=4,77 ; 2,181 ; 1,488 \AA)$.

Chemical composition of the Yany-Kurgan dolomite is represented in Table 3. 


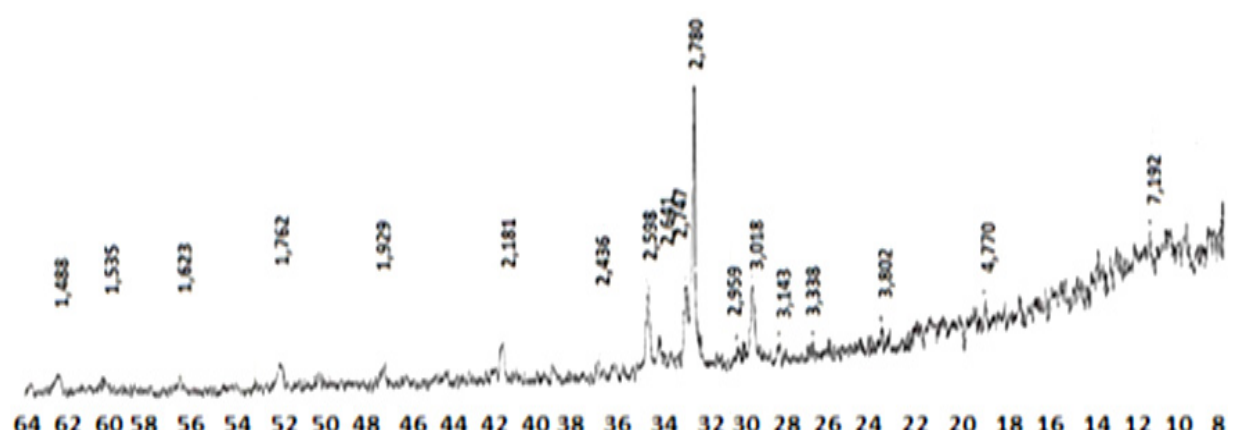

Fig. 1. An X-ray picture of the PC M500 DO

Table 3: The dolomite chemical composition

\begin{tabular}{lcccccccccc}
\hline Component & \multicolumn{10}{c}{ Content of oxides, mas. \% } \\
\cline { 2 - 7 } & $\mathrm{SiO}_{2}$ & $\mathrm{CaO}$ & $\mathrm{Al}_{2} \mathrm{O}_{3}$ & $\mathrm{Fe}_{2} \mathrm{O}_{3}$ & $\mathrm{MgO}$ & $\mathrm{Na}_{2} \mathrm{O}$ & $\mathrm{K}_{2} \mathrm{O}$ & $\mathrm{MnO}$ & $\mathrm{P}_{2} \mathrm{O}_{5}$ & Calcination loss \\
Dolomite & 7,11 & 26,72 & 1,47 & 0,76 & 20,43 & 0,57 & 0,27 & 0,06 & 0,01 & 42,44 \\
\hline
\end{tabular}

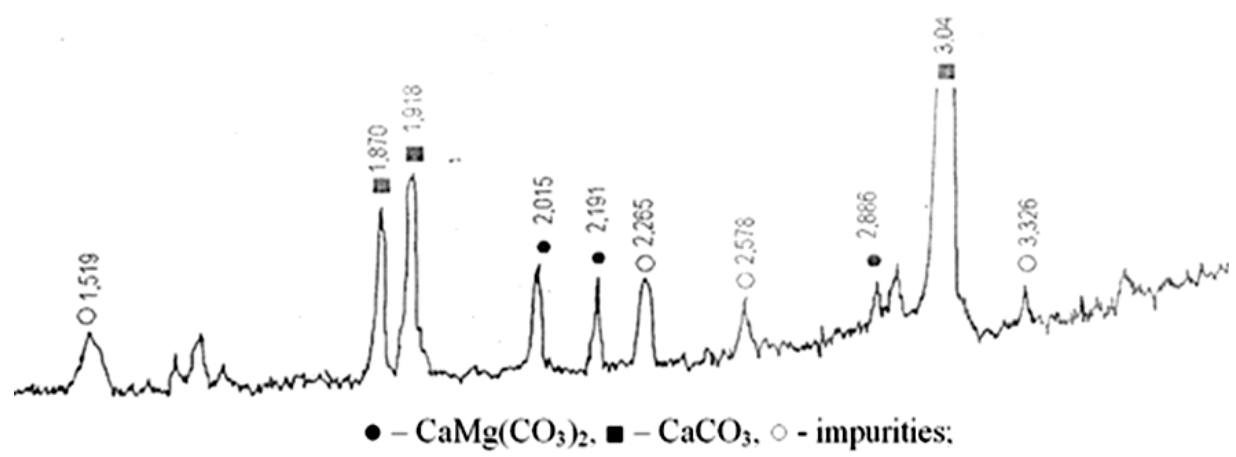

Fig. 2. The Yany-Kurgan dolomite X-ray picture

The X-ray picture permitted to identify such minerals as dolomite $(d=2,898 ; 2,191 ; 2,015$; $1,785 \AA)$, calcite $(d=3,038 ; 2,09 ; 1,874 \AA$ ) and silica $(d=3,343 ; 1,813 ; 1,539 \AA)$.

With the purpose of obtaining composite cements the Yany-Kurgan dolomite, ground to specific surface of $3200 \mathrm{~cm}^{2} / \mathrm{g}$, has been added to the Portland cement in number of $10,20,30,40 \%$. For studying of effect of the additives on the cement properties we have determined the cement setting time. The obtained data are represented in Table 4.

It is necessary to notice, that setting terms of the cement with the dolomite in all the cases are considerably more, that allows to reduce the gypsum quantity used at the grinding a clinker.

It is known, that the most reliable technique for determination of efficiency of mineral additives is determination of physicomechanical characteristics of a binding material (compression strength).

For studying of the dolomite effect on the Portland cement physicomechanical characteristics we determined strength properties of the cement cubic samples in the size of $2 \times 2 \times 2 \mathrm{~cm}$ at the age of 3,7 and 28 hardening days.

Table 4: Effect of the dolomite additives on the cement setting time

\begin{tabular}{lccc} 
PC500 AF Dolomite & \multicolumn{2}{c}{ Setting time, min } \\
& & The beginning & The end \\
\hline $100 \%$ & $0 \%$ & $1 \mathrm{~h} 20 \mathrm{~min}$ & $5 \mathrm{~h} 15 \mathrm{~min}$. \\
$90 \%$ & $10 \%$ & $1 \mathrm{~h} 46 \mathrm{~min}$ & $4 \mathrm{~h} 40 \mathrm{~min}$. \\
$80 \%$ & $20 \%$ & $1 \mathrm{~h} 58 \mathrm{~min}$ & $5 \mathrm{~h} 05 \mathrm{~min}$. \\
$70 \%$ & $30 \%$ & $2 \mathrm{~h} 10 \mathrm{~min}$ & $5 \mathrm{~h} 10 \mathrm{~min}$. \\
$60 \%$ & $40 \%$ & $2 \mathrm{~h} 30 \mathrm{~min}$ & $4 \mathrm{~h} 55 \mathrm{~min}$. \\
\hline
\end{tabular}


Apparently from Table 5, addition of the dolomite up to $30 \%$ has not lowered strength of the samples. The table data show, that inclusion of the dolomite in the Portland cement composition increases its strength on $8,6 \%$ in a case of $10 \%$ of the dolomite, for $20 \%$ on $11,8 \%$, for $30 \%$ on $12,9 \%$; at the addition of $40 \%$ the cement strength decreases on $1,1 \%$.

Table 5: Strength properties of the cement with the dolomite additive

\begin{tabular}{lcccc}
\hline Initial material & Quantity of the additive, \% & \multicolumn{3}{c}{ Ultimate stress, MPa } \\
& & 3 days & 7 days & 28 days \\
& & $R_{\text {compr }}$ & $R_{\text {compr }}$ & $R_{\text {compr }}$ \\
\hline PC500 AF & - & 29 & 38,4 & 46,3 \\
PC500 AF + dolomite & 10 & 34 & 43,8 & 50,3 \\
& 20 & 35,6 & 44,7 & 51,8 \\
& 30 & 36,9 & 45 & 52,3 \\
& 40 & 28,8 & 37,5 & 45,9 \\
\hline
\end{tabular}

The strength growth speaks that at the replacement of a part of the cement by the dolomite with the same fineness degree the total content of high-base clinker minerals $\left(\mathrm{C}_{3} \mathrm{~S}, \mathrm{C}_{2} \mathrm{~S}, \mathrm{C}_{3} \mathrm{~A}, \mathrm{C}_{4} \mathrm{AF}\right)$ in the binding agent's composition decreases. Besides the dolomite particles consolidate the binding agent's structure and eo ipso increase its durability at much smaller cement consumption. Such the changes in the ratios of high-base minerals in composite cements' composition at their hydration and hardening promote formation basically low-base calcium hydrosilicates.
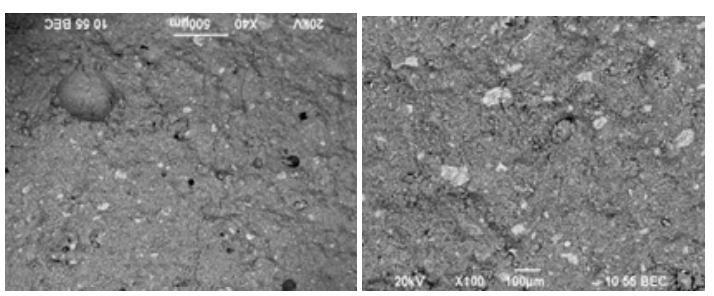

a) the additive-free cement

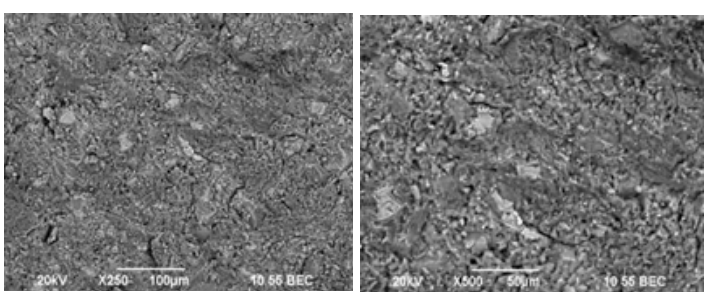

b) $10 \%$ of the dolomite

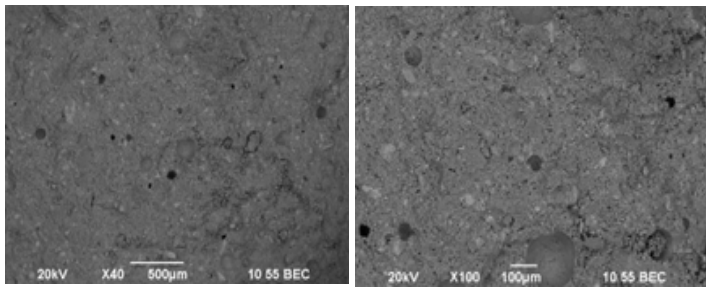

c) $20 \%$ of the dolomite
In addition, the dolomite particles play a role of a micro filler, on which surface there is the cement hydration and formation of a crystalline high-strength stone. Evidently in the presence of the dolomite there is activation of the hydration processes of clinker minerals, especially $\mathrm{C}_{4} \mathrm{AF}$ and $\mathrm{C}_{3} \mathrm{~A}$, with formation of additional quantity of hydro carboaluminates, which compact and strengthen the cement stone structure. Fig. 3 represents microphotos of cleavages of the hardened cement stone, which show consolidation of the stone structure at the dolomite addition.

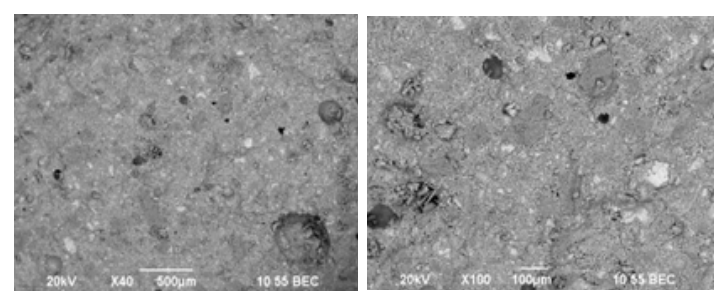

d) $30 \%$ of the dolomite
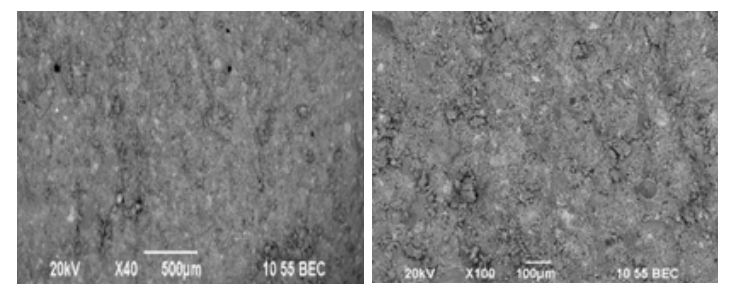

e) $40 \%$ of the dolomite

Fig. 3. Microphotos of cleavages of the hardened cement stone with the dolomite additives

The second additive applied for obtaining composite cements was the waste formed at benefication of polymetallic ores.

The concentration tailings of polymetallic ores - barium carbonate tailings - are a fine-grain 
product that does not require additional grinding before the use. Basic minerals contained in the tailings are dolomite (50-60\%), limestone $(10-15 \%)$, barite $(10-20 \%)$, clay substances $(5-8 \%)$, ore minerals (2-3\%). The ore minerals include iron, lead and rare metal sulphides.

The granulometric composition of the waste: $25-30 \%$ of grains with a particle size less than 25 microns; 55 - $65 \%$ of grains - from 25 to 85 microns; $10-15 \%$ coarse particles - > 200 microns. The possibility of obtaining composite cements at addition of up to $40 \%$ of the waste has been experimentally proved. The clinker minerals C3A and C4AF interact with calcium and magnesium carbonates that are a part of the tailings with formation of complex compounds - hydro carboaluminates $3 \mathrm{CaO} \cdot \mathrm{Al}_{2} \mathrm{O}_{3} \cdot \mathrm{CaCO}_{3} \cdot 11 \mathrm{H}_{2} \mathrm{O}$, $3 \mathrm{CaO} \cdot \mathrm{Al}_{2} \mathrm{O}_{3} \cdot \mathrm{MgCO}_{3} \cdot 11 \mathrm{H}_{2} \mathrm{O}$ and a metastable analogue of ettringite $3 \mathrm{CaO} \cdot \mathrm{Al}_{2} \mathrm{O}_{3} \cdot 3 \mathrm{CaSO} \mathrm{C}_{4} \cdot 31 \mathrm{H}_{2} \mathrm{O}$ identified by an X-ray phase method in the cements' hydration products. Formation of these compounds promotes hardening a structure and increase in strength and corrosion resistance of the cement stone. Increase in the amount of chemically bound water in the hydro carboaluminates and the presence of barium sulfate, added with the tailings, increase protective properties of composite cements from gamma $\mathrm{X}$-ray radiation.

Also we have studied effect of polymetallic ores' concentration tails on properties of a composite slag-alkaline binding material and a concrete.

On the basis of the data about manufacture of slag-alkaline concretes ${ }^{14}$ it is known, that a homogeneous structure of a material, determining its physicomechanical properties, depends on uniform distribution of an alkaline component in a concrete mass that is especially important at use of the production wastes with low alkali content.

The mechanism of action of the above mentioned additive and physical and chemical investigations of a phase composition of hydration products of a composite slag-alkaline binding material is considered below. Samples hardened in conditions of heat wet processing according a mode of $4+3+6+3$.

Addition in a structure of the binding agent, including an electro thermal phosphoric slag, the portland cement clinker and a soda-sulphate mixture, of the waste formed at benefication of polymetallic ores and contained calcium, magnesium and barium oxides, which enter into exchange reactions with the soda-sulphate mixture, leads to formation of sodium hydroxide, which increases alkalinity of the medium that accelerates dispersion of the slag glass and, by this reason, promotes the binding agent's hydration.

The mechanism of action of the polymetallic ores' concentration waste on a composition and properties of a binding agent can be described by chemical reactions:

$$
\begin{aligned}
& \mathrm{CaSiO}_{5}+5 \mathrm{H}_{2} \mathrm{O}=\mathrm{Ca}_{2} \mathrm{SiO}_{4} \cdot 4 \mathrm{H}_{2} \mathrm{O}+\mathrm{Ca}(\mathrm{OH})_{2} \\
& \mathrm{Ca}_{2} \mathrm{SiO}_{4}+4 \mathrm{H}_{2} \mathrm{O}=\mathrm{Ca}_{2} \mathrm{SiO}_{4} \cdot 4 \mathrm{H}_{2 \mathrm{O}} \\
& \mathrm{Ca}_{3}\left(\mathrm{AlO}_{3}\right)_{2}+6 \mathrm{H}_{2} \mathrm{O}=\mathrm{Ca}_{3}\left(\mathrm{AlO}_{3}\right)_{2} \cdot 6 \mathrm{H}_{2} \mathrm{O}
\end{aligned}
$$

Hardness of the material continues to increase for a long time. A principal cause of it is distribution of hydration processes deep into the cement grains ${ }^{15}$. Interaction of a soda-sulphate mixture with the concentration waste containing calcium, magnesium and barium oxides occurs according to the following scheme:

\section{I}

$\mathrm{Na}_{2} \mathrm{CO}_{3}+\mathrm{Ca}(\mathrm{OH})_{2}=\mathrm{CaCO}_{3}+2 \mathrm{NaOH}$

$\mathrm{Na}_{2} \mathrm{CO}_{3}+\mathrm{Ba}(\mathrm{OH})_{2}=\mathrm{BaCO}_{3}+2 \mathrm{NaOH}$

$\mathrm{Na}_{2} \mathrm{CO}_{3}+\mathrm{Mg}(\mathrm{OH})_{2}=\mathrm{MgCO}_{3}+2 \mathrm{NaOH}$

II

$\mathrm{Na}_{2} \mathrm{SO}_{4}+\mathrm{Ca}(\mathrm{OH})_{2}=\mathrm{CaSO}_{4}+2 \mathrm{NaOH}$

$\mathrm{Na}_{2} \mathrm{SO}_{4}+\mathrm{Mg}(\mathrm{OH})_{2}=\mathrm{MgSO}_{4}+2 \mathrm{NaOH}$

$\mathrm{Na}_{2} \mathrm{SO}_{4}+\mathrm{Ba}(\mathrm{OH})_{2}=\mathrm{BaSO}_{4}+2 \mathrm{NaOH}$

Formation of sodium hydroxide increases the medium alkalinity, accelerates the dispersion processes and promotes the binding agent hydration.

The mechanism of sodium hydroxide action can be represented as a peptization process. Peptization provides repulsion on farther distances, where intermolecular attraction forces prevail. Peptization may be realized by a surface dissociation method. A double electrical layer forms at interaction of sodium hydroxide with particles of a disperse system. There is formation the soluble compounds, which accelerate the dispersion process ${ }^{16}$. 
Presence of aluminium oxides in the waste, which content in the electro thermal phosphoric slag is insufficient, provides course of hydration processes in a direction of synthesis of alkaline hydro alumosilicates. The process is mainly caused by hydration of metaaluminate with simultaneous precipitation of aluminium hydroxide according to the reaction

$$
2 \mathrm{Ca}\left(\mathrm{AlO}_{2}\right)_{2}+10 \mathrm{H}_{2} \mathrm{O}=\mathrm{Ca}_{2} \mathrm{Al}_{2} \mathrm{O}_{5} \cdot 7 \mathrm{H}_{2} \mathrm{O}+2 \mathrm{Al}(\mathrm{OH})_{3}{ }^{16}
$$

The barium containing in the binding material leads to complication of a phase composition of formed compounds. At mixing of the binding material with the soda-sulphate solution, the barium ions enter into an exchange reaction with calcium ions therefore there is penetration of $\mathrm{Ba}^{2+}, \mathrm{Cl}^{-}$and $\mathrm{SO}_{4}^{2-}$ ions into a structure of formed phases.

So, according to the X-ray analysis a phase composition of the binding material's hydration products (Fig. 4) includes barium-containing vencite $\mathrm{Ba}_{4-5} \mathrm{Ca}_{4-5} \mathrm{Al}_{9} \mathrm{Si}_{12} \mathrm{O}_{42}\left(\mathrm{SO}_{4}\right)_{2}(\mathrm{OH})_{5}(\mathrm{~d} / \mathrm{n}=0,501 ; 0,460$; $0,354 ; 0,346 ; 0,315 ; 0,297 ; 0,235 \mathrm{~nm})$, a compound of a type of $\mathrm{BaOAl}_{2} \mathrm{O}_{34} \mathrm{SiO}_{4} \mathrm{BaCl}_{2} \mathrm{ZH}_{2} \mathrm{O}(\mathrm{d} / \mathrm{n}=0,307$; $0,328 ; 0,297 ; 0,280 ; 0,270 \mathrm{~nm})$, and also tobermorite $\mathrm{C}_{5} \mathrm{~S}_{6} \mathrm{H}_{5}(\mathrm{~d} / \mathrm{n}=0,328 ; 0,307 ; 0,297 ; 0,280 ; 0,700 \mathrm{~nm})$.

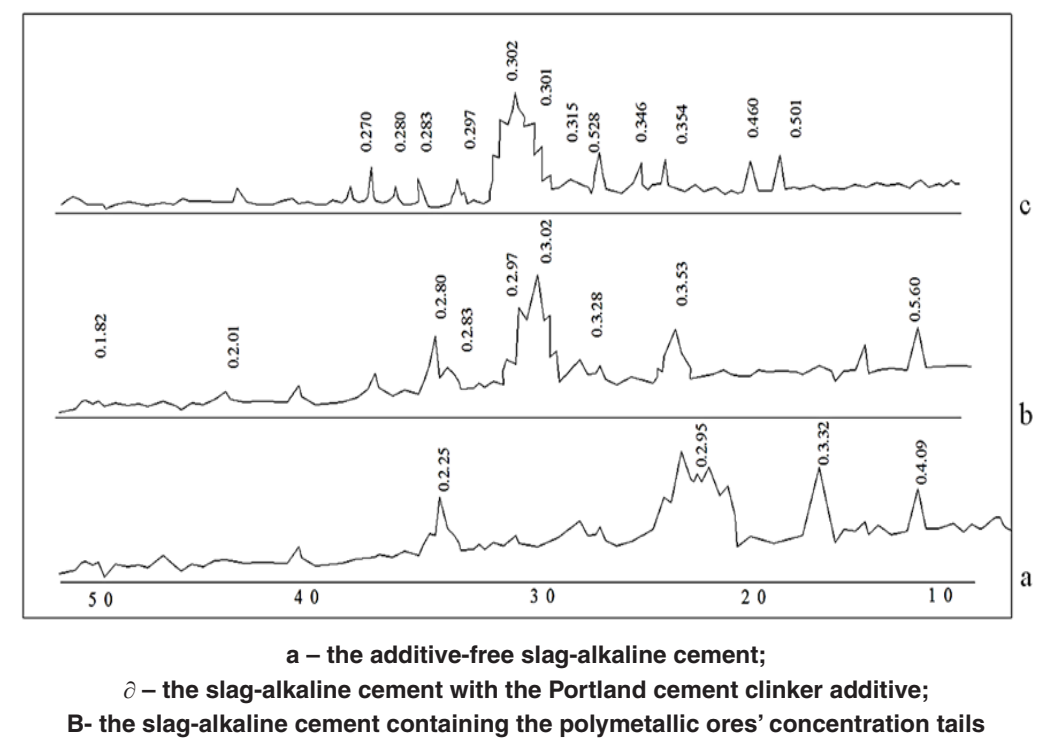

Fig. 4. X-ray pictures of hydration products of the composite slag-alkaline cementing material

The differential thermal analysis (Fig. 5) confirms the formation of previously mentioned compounds: tobermorite $\mathrm{C}_{5} \mathrm{~S}_{6} \mathrm{H}_{5}$ - by presence of endoeffects at 428 and $563 \mathrm{~K}$ and an exoeffect at $1073 \mathrm{~K}$, and minerals of a cancrenite group, which includes vencite and $\mathrm{BaOAI}_{2} \mathrm{O}_{34} \mathrm{SiO}_{4} \mathrm{BaCl}_{2} \mathrm{ZH}_{2} \mathrm{O}-$ by exoeffects at 1103 and $1043 \mathrm{~K}$.

Fixing of $\mathrm{SO}_{4}{ }^{2-}$ and $\mathrm{Cl}^{-}$ions by the alkaline hydro alumosilicates formed at the hydration reduces salt formation and corrosion of reinforcement in the concrete.

Addition of the polymetallic ores' concentration waste in the binding agent's structure promotes increase in its frost resistance and strength at all stages of the cement stone solidification owing to formation of more complex compounds containing $\mathrm{SO}_{4}{ }^{2-}$ and $\mathrm{Cl}^{-}$ions and also acceleration of the hydration processes and increase in crystallization rate of formed substances, that, in one's turn, determines the possibility of application of accelerated regimes of the heat wet treatment and normal hardening of the concrete.

Running ability of the slag-alkaline concrete on the basis of electro thermal phosphoric slag and a soda-sulphate mixture considerably increase at addition of modified additives such as the ore benefication waste into the composition of the binding agent. The test results are represented in Table 6.

The phase composition of solidification products of the slag-alkaline hardened stone containing the ores' benefication waste includes tobermorite $\left(\mathrm{C}_{5} \mathrm{~S}_{6} \mathrm{H}_{5}\right)$, barium-containing vencite and a compound of a type of $\mathrm{BaOAl}_{2} \mathrm{O}_{3} 4 \mathrm{SiO}_{2} 4 \mathrm{Ba} \cdot \mathrm{Cl}_{2} \mathrm{ZH}_{2} \mathrm{O}$. 


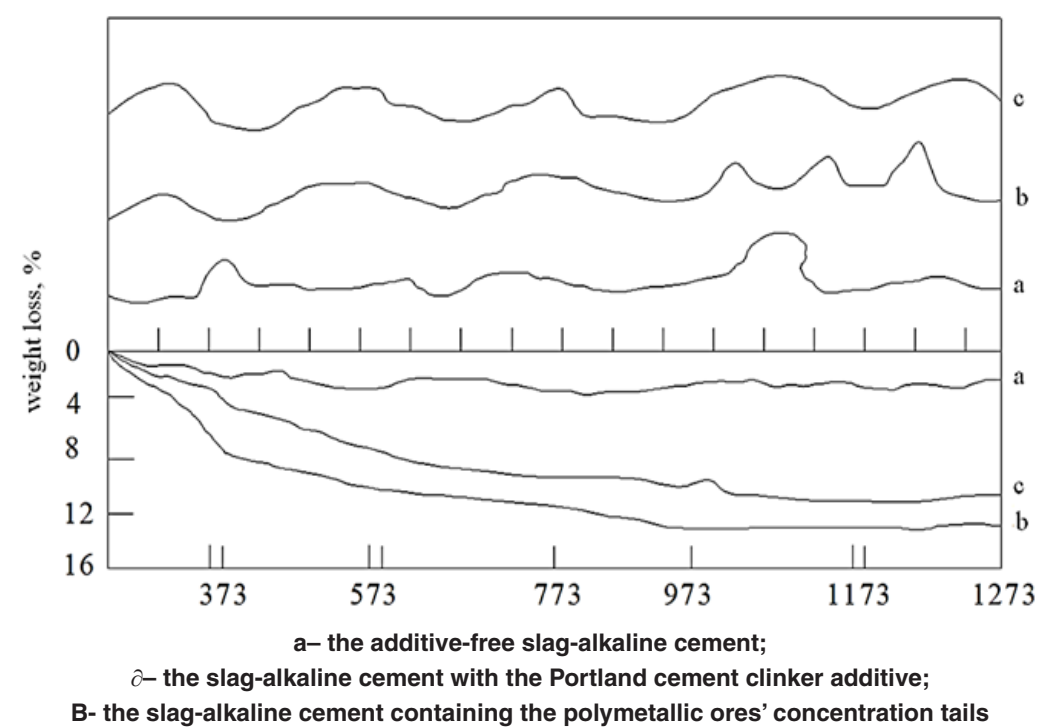

Fig. 5. Thermograms of hydration products of the composite slag-alkaline cementing material

Table 6: Change of strength characteristics of the slag-alkaline binding agent on the basis of electro thermal slag and a soda-sulphate mixture with addition of ores' benefication tails in aggressive mediums

\begin{tabular}{|c|c|c|c|c|c|c|c|c|c|}
\hline \multirow[t]{3}{*}{ A binding agent } & \multirow{3}{*}{$\begin{array}{c}\text { Density of a } \\
\text { soda-sulphate } \\
\text { mixture, } \mathrm{kg} / \mathrm{m}^{3}\end{array}$} & \multicolumn{8}{|c|}{ Bending strength, MPa, after aging, day } \\
\hline & & \multicolumn{2}{|c|}{ Water } & \multicolumn{2}{|c|}{$\begin{array}{c}5 \% \mathrm{Na}_{2} \mathrm{SO}_{4} \\
\text { solution }\end{array}$} & \multicolumn{2}{|c|}{$\begin{array}{c}5 \% \text { lactic acid } \\
\text { solution }\end{array}$} & \multicolumn{2}{|c|}{$\begin{array}{l}5 \% \text { urea } \\
\text { solution }\end{array}$} \\
\hline & & 28 & 180 & 28 & 180 & 28 & 180 & 28 & 180 \\
\hline Additive-free & 1150 & 5,01 & 5,48 & 5,08 & 5,78 & 4,98 & 5,71 & 5,03 & 5,74 \\
\hline $\begin{array}{l}\text { With the additive } \\
\text { (ores' benefication }\end{array}$ & 1150 & 5,48 & 6,18 & 5,91 & 6,73 & 5,83 & 6,67 & 5,89 & 6,93 \\
\hline
\end{tabular}

The electronic microphotograph of the hardened stone with the additive is shown in Figure 6.

In the microphotograph tubular crystals of

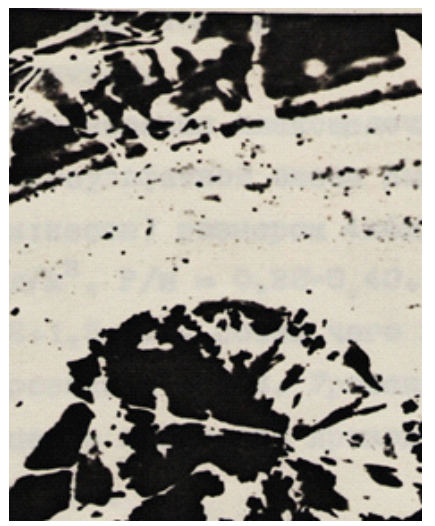

calcium hydrosilicates and polyhedrons, which can be related to vencite are visible.

Resistance of the composite slag-alkaline cement stone with the additive in aggressive 
mediums speaks about formation of concrete with a denser structure, low porosity and presence of stable compounds in the hydration products.

Discussion. Decrease in content of a clinker component in composite cements reduces content of high-base clinker minerals $\mathrm{C}_{3} \mathrm{~S}, \mathrm{C}_{2} \mathrm{~S}, \mathrm{C}_{4} \mathrm{AF}$ and $\mathrm{C}_{3} \mathrm{~A}$ that during hydration promotes formation of basically a low-base form of calcium hydrosilicates such as $\mathrm{CSH}(\mathrm{B})$, which is more strong than their high-base forms. Besides the carbonate particles, containing in the additive, consolidate a concrete or solution structure increasing their durability at considerably smaller cement consumption. The calcium and magnesium hydro carboaluminates, formed as a result of interaction of an aluminate constituent of a clinker and a carbonate component of the additive, promotes consolidation and hardening of the hardened cement stone. The presence of calcium and magnesium hydro carboaluminates and the barium sulphate containing in the waste products of polymetallic ores' benefication can increase protective properties against gamma and $\mathrm{x}$-ray radiation. The research results have shown the possibility of directed control of the hydration process and growth of a cement stone's strength by means of regulation of a cement mineralogical composition and the additive type. During the process there is formation of sodium hydroxide which increases alkalinity of the medium and dispersion. Also it has been established that addition of the ores' benefication waste in a composition of composite slag-alkaline binding materials improve technical and operating properties of composite slag-alkaline concretes.

\section{ACKNOWLEDGEMENT}

The research has been performed in accordance with the concept of small and average scale business development, the Government program on forced industrial innovative development of the Republic of Kazakhstan and the M. Auezov SKSU research plan.

The obtained results can provide solving scientific and technical problems of energy and resource saving. in the field of composite cement manufacture.

\section{REFERENCES}

1. Shubin V.I., Yudovich B.E., Dmitriyev A.M., Zubekhin S.A. New and perspective kinds of cements for the building complex // Cement and its application., 2001, 6. 135-140.

2. Eitin Z.B. Multicomponent cements / Z.B. Eitin, B.E. Yudovig // International conference on cement chemistry and technology. Moscow, 4-8 December, 2000, 1, 94-108.

3. Kozlova V.K. Features of a composition of hydration products of composite Portland cements with carbonate-containing additives / V.K. Kozlova, A.M. Manokha, V.P. Skakun, Ye.Yu Malova, Ye. V. Bozhok // Cement and its application. July-August., 201, 2, 102-105.

4. Kozlova V.K. Status and development prospects of multicomponent low-clinker cementing agents manufacture / V.K. Kozlova, Ye.V. Shkrobko, Ye.Yu. Malova, A.N. Afankov, V.V. Konyin // Polzunov's bulletin., 2002, 1 , 72-75.

5. Catinaud S., Beaudoin J.J., Marchand J. Influence of limestone addition on calcium leaching mechanisms in cement based materials // Cement and Concrete Research., 2000, 30, 1961-1968.

6. Uchikawa H., Hanehara S., Hirao H. Influence of microstructure on the physical properties of concrete prepared by substituting mineral powder for part of fine aggregate // Cement and Concrete Research., 1996, 26, 101111.

7. Kuzel H.J., Poellmann H. Hydration of $\mathrm{C} 3 \mathrm{~A}$ in the presence of $\mathrm{Ca}(\mathrm{OH})_{2} \cdot \mathrm{CaSO}_{4} \cdot 2 \mathrm{H}_{2} \mathrm{O}$ and $\mathrm{CaCO}_{3} / /$ Cement and Concrete Research., 1991, 21, 885-895.

8. Timashev V.V., Kolbasov V.M. Properties of cements with carbonate additives // Cement, 1981, 10, 10-12.

9. Sawicz Z., Heng S.S. Durability of concrete with addition of limestone powder / Magazine of Concrete Research., 1996, 48, 131-137.

10. Sivkov S.P. Thermodynamic analysis of phase formation at solidification of carbonatecontaining cements // Cement and its application., 2008, 6, 140-150 
11. Bikbau M.Ya. Prospects of introduction of cement's mechanochemical processing technology // XXI century building materials, equipment, Technologies., 2007, 9, 125-135.

12. Bikbau M.Ya., Mochalov V.N., Chen Lun Manufacture of mechanochemically activated cements with low water requirement // Cement and its application., 2008, 3, 150-155.

13. Khudyakova T.M., Verner V.F., Gosporyan Ye.V. Complex use of polymetallic ores' benefication wastes for building materials manufacture. - South Kazakhstan science and education., 2003, 32, 185-188.

14. Sarsenbayev B.K., Yestemesov Z.A., Aimenov Zh.T., Sarsenbayev N.B., Aimenov A.Zh. // Slag-alkaline cementing materials and concretes. - Shymkent: Publ. House of $M$. Auezov SKSU., 2016, 360.

15. Nekrasov B.V. Course of general chemistry. Moscow: Chemical literature., 1954, 648-649.

16. Baranova V.I. Colloidal chemistry. - Moscow: Higher school., 1983, 79-80. 